(C) 2006 by The Society for Healthcare Epidemiology of America. All rights reserved. 0899-823X/2006/2708-0004

\title{
Impact of Postdischarge Surveillance on Surgical Site Infection Rates for Several Surgical Procedures: Results From the Nosocomial Surveillance Network in The Netherlands
}

\section{Judith Manniën, MSc; Jan C. Wille; Ruud L. M. M. Snoeren; Susan van den Hof, PhD}

From the National Institute for Public Health and the Environment, Bilthoven (J.M., S.v.d.H.), Dutch Institute for Healthcare Improvement, CBO, Utrecht (J.C.W.), and St. Elisabeth Hospital, Tilburg (R.L.M.M.S.), The Netherlands.

Address requests for reprints to Dr. Judith Manniën (Postbak 75), National Institute for Public Health and the Environment, PO Box 1, Bilthoven, The Netherlands (Judith.Mannien@rivm.nl).

OBJECTIVE. To compare the number of surgical site infections (SSIs) registered after hospital discharge with respect to various surgical procedures and to identify the procedures for which postdischarge surveillance (PDS) is most important.

DESIGN. Prospective SSI surveillance with voluntary PDS. Recommended methods for PDS in the Dutch national nosocomial surveillance network are addition of a special registration card to the outpatient medical record, on which the surgeon notes clinical symptoms and whether a patient developed an SSI according to the definitions; an alternative method is examination of the outpatient medical record.

SETTING. Hospitals participating in the Dutch national nosocomial surveillance network between 1996 and 2004.

RESULTS. We collected data on 131,798 surgical procedures performed in 64 of the 98 Dutch hospitals. PDS was performed according to one of the recommended methods for 31,134 operations (24\%) and according to another active method for 32,589 operations $(25 \%)$, and passive PDS was performed for 68,075 operations $(52 \%)$. Relatively more SSIs were recorded after discharge for cases in which PDS was performed according to a recommended method (43\%), compared with cases in which another active PDS method was used (30\%) and cases in which passive PDS was used (25\%). The highest rate of SSI after discharge was found for appendectomy (79\% of operations), followed by knee prosthesis surgery (64\%), mastectomy $(61 \%)$, femoropopliteal or femorotibial bypass $(53 \%)$, and abdominal hysterectomy $(53 \%)$.

CONCLUSIONS. For certain surgical procedures, most SSIs develop after discharge. SSI rates will be underestimated if no PDS is performed. We believe we have found a feasible and sensitive method for PDS that, if patients routinely return to the hospital for a postdischarge follow-up visit, might be suitable for use internationally. 
Surgical site infections (SSIs) are the second most common type of nosocomial infection, after urinary tract infection, and account for approximately $17 \%$ of all nosocomial infections. ${ }^{1}$ SSIs lead to increased morbidity and costs, because patients who develop SSIs have a longer hospital stay, are more likely to be readmitted, and are more likely to die. ${ }^{2-10}$ SSI rates, especially in clean surgery in which no bacteria-colonized tract of the body is opened, are considered an indicator of the quality of surgical and postoperative care given in hospitals.

Over the past decade, there has been an increasing trend toward shorter length of hospital stay and use of ambulatory day surgery. Thus, an increasing proportion of SSIs occur after the patient has left the hospital, which makes postdischarge surveillance (PDS) increasingly important. If no PDS is performed, SSIs will be missed, and the recorded infection rates will be underestimations of the real infection rates. Furthermore, interhospital comparison may not be valid if the sensitivity and specificity of the PDS methods used are not similar.

Unlike for inpatient SSI surveillance, there is no international consensus on the optimal method for PDS. ${ }^{3,11,12}$ Two challenges for a good method of PDS are to follow up all patients and to accurately diagnose the presence or absence of an SSI. Direct examination of the wounds of all patients by a trained professional is often used as the "gold standard" for detection of SSIs. For PDS this method is, however, labor-intensive, difficult to perform routinely, and very expensive. ${ }^{12}$ Therefore, the third challenge is feasibility, with limited time investment.

In The Netherlands in 1998, a literature review was conducted to assess whether there was a method for PDS that would be feasible for all hospitals, in terms of a high sensitivity and a low time investment. ${ }^{13}$ As a result of that study, in the Dutch national nosocomial surveillance network PREZIES ("Preventie van Ziekenhuisinfecties door Surveillance"), 2 methods for PDS are recommended. The first method is addition of a special registration card to the outpatient medical record, on which the surgeon notes clinical symptoms and whether a patient developed an SSI according to the definitions. This is recommended as a feasible and reliable method for PDS in The Netherlands, because almost every patient is seen again by the surgeon after hospital discharge. A crucial point is that the surgeon returns the registration cards of all patients who visited the outpatient clinic. If the feedback and collaboration of the surgeon are suspected to be unsatisfactory, the method needs to be validated internally. If unsatisfactory validity is observed, (additional) examination of all outpatient medical records is the alternative recommended method for PDS. A condition of this method is that the medical reporting in the outpatient record is sufficient.

Examples of other-not recommended-active PDS methods that can be used are questionnaires sent to patients, questionnaires sent to surgeons, and telephone interviews with patients. If no active PDS is performed, SSIs can still be detected accidentally (for instance, when patients are hospitalized for this type of infection). This is called "passive" PDS.

Studies that examine the value added by PDS to SSI surveillance often focus on only one or a few surgical procedures and usually involve a single hospital. $3,6,8,14,15$ With this approach, it is impossible to discover the procedures for which PDS is most essential, which may be important for efficient allocation of resources. In the present study, we analyzed PREZIES data on several surgical procedures from 62 hospitals. The purpose was to compare the number of SSIs registered after discharge with respect to various surgical procedures and to identify the procedures for which PDS is most important. In addition, we compared 
SSI rates obtained with recommended PDS methods and those obtained with other active PDS methods and with passive PDS.

\section{METHODS}

The PREZIES network in The Netherlands started in 1996 with surveillance of SSIs. Participation in PREZIES is voluntary. Hospitals are free to make a selection of procedures they want to include in the surveillance. They can also choose how long they want to participate, but a minimum of 3 months is recommended, to obtain enough data for reliable results. According to the PREZIES protocol, patients younger than 1 year are excluded, as well as patients with an infection at hospital admission. For the current study, patients were also excluded if the method for PDS was unknown or if the date of infection was unknown.

The definition of an SSI used is based on the definition of the Centers for Disease Control and Prevention, ${ }^{11,16}$ which was translated by the Dutch Working Party on Infection Prevention. ${ }^{17}$ We have chosen to evaluate both deep incisional and organ-space SSIs under the umbrella term "deep SSI."

According to the CDC definition of nosocomial infection, an SSI is an infection that occurs within 30 days after the operation if no implant is left in place or within 1 year after the operation (only deep SSIs) if an implant is left in place and the infection appears to be related to the operation. An implant is understood to mean a non-human-derived implantable foreign body (eg, a prosthetic heart valve, a nonhuman vascular graft, a mechanical heart, or a hip prosthesis) that is permanently placed in a patient during surgery. To ensure that PDS was completed for all records in the database, we excluded data from the year 2004 for specialties in which implants are often used; this was done for bone surgery and vascular surgery.

The person responsible for the surveillance (predominantly the infection control professional) ensures that everybody involved collects data according to the surveillance protocol and uses the right definitions. To monitor the quality and reliability of the surveillance data in PREZIES, the surveillance at each participating hospital is validated at least once every 3 years. The following information is collected on the patients, procedures, hospitals, and infections: the patient's sex and date of birth; the dates of admission, surgery, and discharge the type and duration of the procedure; the American Society of Anesthesiologists physical status score ${ }^{18}$ for the severity of any underlying disease; the wound contamination class; ${ }^{11}$ whether antibiotic prophylaxis was given (yes or no); the type of procedure (elective or emergency); the type of hospital (university or peripheral); the date of infection; and the type of infection (superficial incisional, deep incisional, or organ-space).

Hospitals in the PREZIES network are allowed to change the method used for PDS over time and to perform different methods for different surgical procedures. Every time a hospital sends in registered data, the infection control professional states which method for PDS is used for which procedures. A distinction is made between recommended PDS, other active PDS, and passive (no active) PDS.

SSI rates were determined according to PDS method and according to type of procedure. The percentage of SSIs diagnosed after discharge was compared between PDS methods and between procedures. Changes over time were examined. 
Comparative analysis of categorical variables was performed using a $\boldsymbol{X}^{2}$ test with the Yates correction. Continuous variables were analyzed using the Student $t$ test for normally distributed variables and the Mann-Whitney $U$ test for nonnormally distributed variables. The nonparametric Kruskal-Wallis test was used to compare the values of a nonnormally distributed variable between multiple independent groups. The $P$ values of all tests of significance were 2 -tailed, and a $P$ value of .05 or less was considered to indicate statistical significance. All statistical analyses were performed using SAS software, version 8.2 (SAS Institute).

\section{RESULTS}

The PREZIES network has collected SSI data on 143,321 procedures from 1996 to 2004. These data were collected at 73 hospital sites in 64 hospitals of the total of 98 hospitals in The Netherlands. One record was excluded because the infection date was unknown, and 8,122 records were excluded because the method for PDS was unknown. We also excluded vascular surgery and bone surgery data from 2004 (records on 3,400 procedures), because the 1-year postdischarge follow-up period for implant surgery had not passed yet. Therefore, the results we describe are based on data for 131,798 records from 73 hospital sites (hereafter referred to as "hospitals"). The number of hospitals participating yearly varied between 29 and 50 during the period 1996-2003 and was 11 in 2004. This low number of participating hospitals in 2004 occurred partly because not all hospitals had sent in their data yet at time the analyses were performed and partly because the records for vascular and bone surgery were excluded.

PDS was performed according to one of the recommended methods for 31,134 operations (24\%) and according to another active method in 32,589 operations $(25 \%)$, and passive PDS was performed in 68,075 operations $(52 \%)$ (Table 1 ). Relatively more postdischarge SSIs were recorded for cases in which PDS was performed according to one of the recommended methods (43\% of operations), compared with cases in which other active PDS was used $(30 \%)$ or passive PDS was used $(25 \%)$.

Table 1 Comparison of the Number of Surgical Site Infections (SSIs) Identified by Various Postdischarge Surveillance (PDS) Methods

\begin{tabular}{|c|c|c|c|c|}
\hline PDS method used & $\begin{array}{c}\text { No. of } \\
\text { operations }\end{array}$ & No. of SSIs & SSI rate, \% & $\begin{array}{c}\text { No. (\%) of SSIs } \\
\text { that developed after } \\
\text { hospital discharge }\end{array}$ \\
\hline Recommended PDS & 31,134 & 1,154 & 3.7 & $492(43)$ \\
\hline Other active PDS & 32,589 & 1,036 & 3.2 & $306(30)$ \\
\hline Passive PDS & 68,075 & 2,086 & 3.1 & $514(25)$ \\
\hline \hline Total & 131,798 & 4,276 & 3.2 & $1,312(31)$ \\
\hline
\end{tabular}

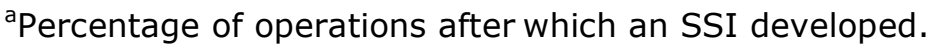


In Table 2, the type of SSI detected-superficial or deep-is compared for SSIs that developed during and after hospitalization, stratified by PDS method. For 49 operations, information on the type of SSI was missing, and therefore these operations are excluded from the analysis. Relatively more superficial SSIs were recorded when PDS was performed according to one of the recommended PDS methods. A relatively smaller proportion of superficial SSIs were recorded after discharge ( $48 \%$ of SSIs) than before discharge (57\%), but the proportion of superficial SSIs identified after discharge was higher with use of a recommended PDS method than with use of other active and passive PDS methods. The differences between PDS methods in the types of SSI identified were larger for postdischarge SSIs $(P<.001)$ than for in-hospital SSIs $(P=.17)$.

TABLE 2 Comparison of the Types of Surgical Site Infection (SSI) Identified by Various Postdischarge Surveillance (PDS) Methods During and After Hospitalization

\begin{tabular}{|c|c|c|c|c|c|c|}
\hline \multirow[b]{2}{*}{ PDS method used } & \multicolumn{3}{|c|}{ SSI during hospitalization } & \multicolumn{3}{|c|}{ SSI after discharge } \\
\hline & $\begin{array}{l}\text { No. of } \\
\text { SSIs }\end{array}$ & $\begin{array}{c}\text { Deep, } \\
\%\end{array}$ & $\begin{array}{c}\text { Superficial, } \\
\%\end{array}$ & $\begin{array}{l}\text { No. of } \\
\text { SSIs }\end{array}$ & $\begin{array}{l}\text { Deep, } \\
\%\end{array}$ & $\begin{array}{c}\text { Superficial, } \\
\%\end{array}$ \\
\hline $\begin{array}{l}\text { Recommended } \\
\text { PDS }\end{array}$ & 646 & 40 & 60 & 492 & 45 & 55 \\
\hline Other active PDS & 715 & 45 & 55 & 304 & 49 & 51 \\
\hline Passive PDS & 1,558 & 43 & 57 & 512 & 61 & 39 \\
\hline Total & 2,919 & 43 & 57 & 1,308 & 52 & 48 \\
\hline
\end{tabular}

Figure 1 shows that the percentage of hospitals that predominantly performed PDS according to one of the recommended methods increased from 24\% in 1996 to $50 \%$ in 2003 . Both a shorter length of stay and use of a recommended PDS method result in a higher proportion of infections being detected after discharge. Only for total hip prosthesis surgery, a frequently performed procedure, was there a clear decrease in the median length of stay for patients without an SSI observed, from 13 days during 1996-1999 to 10 days during 2000-2003 $(P<.001$, data not shown). Simultaneously, there was an increase in the percentage of SSIs that developed after discharge for this procedure, from $23 \%$ to $44 \%(P<.001$, data not shown). This increase was similar for all PDS methods $(P=.83)$. Thus, the relatively high proportion of postdischarge SSIs detected by the recommended PDS method, compared with other methods, truly is the result of using this PDS method and cannot be explained by shorter hospital stays. However, the mean proportion of SSIs associated with total hip surgery that were detected after discharge during the period 1996-2003 gives an underestimation of the proportion of SSIs detected after discharge in recent years. 


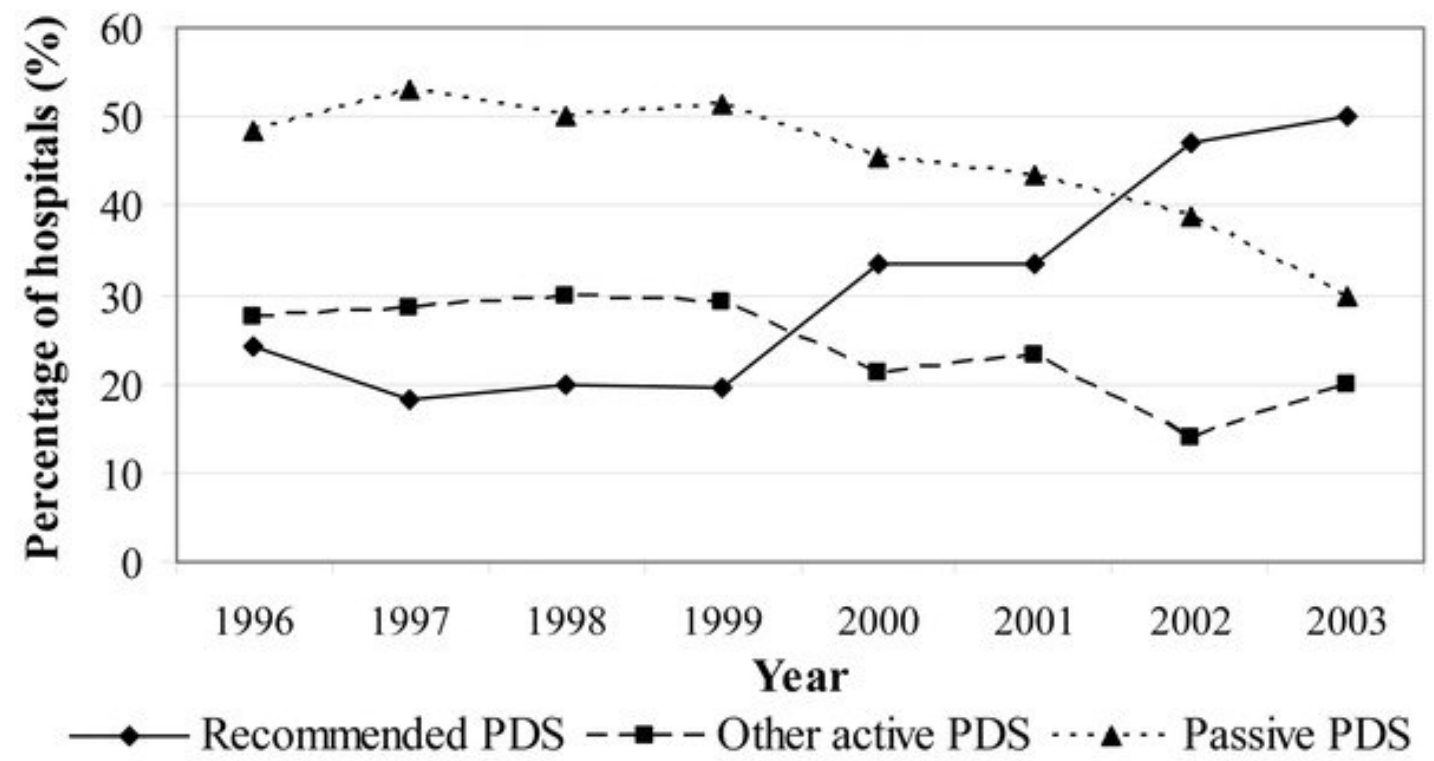

FIGURE 1. Predominant postdischarge surveillance (PDS) methods used by hospitals in The Netherlands, by year, 1996-2003. Data from 2004 were excluded from this figure because of the relatively small number of hospitals that reported in that year.

Table 3 shows the number of SSIs identified, overall and after discharge, by recommended PDS and passive PDS, according to the type of surgical procedure. For 10 procedures, a higher total SSI rate was recorded with use of recommended PDS than with use of passive PDS; the opposite was the case for 4 procedures. Relatively fewer SSIs were recorded after discharge with use of passive PDS, compared with recommended PDS, for 13 of 14 procedures. The highest percentage of postdischarge SSIs (ie, postdischarge SSIs as a percentage of all SSIs) identified by recommended PDS was found for appendectomy (76\%), followed by knee prosthesis surgery $(64 \%)$, mastectomy $(61 \%)$, femoropopliteal or femorotibial bypass (53\%), and abdominal hysterectomy (53\%). 
TABLE 3. Comparison of the Number of Surgical Site Infections (SSIs) Identified by Recommended Postdischarge Surveillance (PDS) and by Passive PDS During and After Hospitalization, According to Surgical Procedure

\begin{tabular}{|c|c|c|c|c|c|c|c|c|}
\hline \multirow[b]{3}{*}{ Procedure $^{a}$} & \multicolumn{4}{|c|}{ Recommended PDS used } & \multicolumn{4}{|c|}{ Passive PDS used } \\
\hline & \multicolumn{2}{|c|}{ All SSIs } & \multicolumn{2}{|c|}{ Postdischarge SSIs } & \multicolumn{2}{|c|}{ All SSIs } & \multicolumn{2}{|c|}{ Postdischarge SSIs } \\
\hline & $\begin{array}{l}\text { No. } \\
\text { of } \\
\text { SSIs }\end{array}$ & $\begin{array}{l}\text { SSI } \\
\text { rate, } \\
\%^{\mathrm{b}}\end{array}$ & $\begin{array}{l}\text { No. } \\
\text { of } \\
\text { SSIs }\end{array}$ & $\begin{array}{l}\text { Percentage } \\
\text { of all SSIs }{ }^{c}\end{array}$ & $\begin{array}{l}\text { No. } \\
\text { of } \\
\text { SSIs }\end{array}$ & $\begin{array}{l}\text { SSI } \\
\text { rate, } \\
\%^{b^{b}}\end{array}$ & $\begin{array}{l}\text { No. } \\
\text { of } \\
\text { SSIs }\end{array}$ & $\begin{array}{l}\text { Percentage } \\
\text { of all SSIs }\end{array}$ \\
\hline Appendectomy & 49 & 6.6 & 37 & 76 & 65 & 4.1 & 23 & 35 \\
\hline $\begin{array}{l}\text { Knee prosthesis } \\
\text { surgery }\end{array}$ & 108 & 2.7 & 69 & 64 & 73 & 1.5 & 37 & 51 \\
\hline Mastectomy & 62 & 6.2 & 38 & 61 & 141 & 4.2 & 59 & 42 \\
\hline $\begin{array}{l}\text { Femoropopliteal or } \\
\text { femorotibial bypass }\end{array}$ & 55 & 18.6 & 29 & 53 & 74 & 8.4 & 21 & 28 \\
\hline $\begin{array}{l}\text { Abdominal } \\
\text { hysterectomy }\end{array}$ & 30 & 2.3 & 16 & 53 & 16 & 1.3 & 1 & 6 \\
\hline $\begin{array}{l}\text { Total hip prosthesis } \\
\text { surgery }\end{array}$ & 277 & 2.7 & 118 & 43 & 303 & 2.7 & 74 & 24 \\
\hline $\begin{array}{l}\text { Repair of } \\
\text { osteopertrochanteric } \\
\text { collum fracture }\end{array}$ & 16 & 7.6 & 5 & 31 & 21 & 3.0 & 2 & 10 \\
\hline $\begin{array}{l}\text { Replacement of head } \\
\text { of femur }\end{array}$ & 89 & 5.7 & 23 & 26 & 139 & 5.3 & 18 & 13 \\
\hline Colon resection & 92 & 11.3 & 23 & 25 & 218 & 11.8 & 6 & 3 \\
\hline $\begin{array}{l}\text { Reconstruction of } \\
\text { aorta }\end{array}$ & 23 & 5.4 & 5 & 22 & 38 & 3.5 & 5 & 13 \\
\hline $\begin{array}{l}\text { Revision of total hip } \\
\text { prosthesis }\end{array}$ & 34 & 6.3 & 7 & 21 & 82 & 6.6 & 10 & 12 \\
\hline $\begin{array}{l}\text { Anterior resection of } \\
\text { rectosigmoid }\end{array}$ & 42 & 13.0 & 7 & 17 & 98 & 11.1 & 6 & 6 \\
\hline $\begin{array}{l}\text { Osteosynthesis of } \\
\text { collum fracture }\end{array}$ & 26 & 3.4 & 3 & 12 & 52 & 4.2 & 4 & 8 \\
\hline $\begin{array}{l}\text { Removal of infected } \\
\text { hip }\end{array}$ & 15 & 10.4 & 0 & 0 & 11 & 4.4 & 2 & 18 \\
\hline
\end{tabular}

a Procedures in which at least 10 SSIs were identified by both PDS methods.

b Percentage of operations after which an SSI developed.

${ }^{c}$ Postdischarge SSIs as a percentage of all SSIs. 
Table 4 shows the number of deep SSIs identified by recommended PDS and by passive PDS during and after hospitalization, according to surgical procedure (procedures for which at least 10 deep SSIs were identified by both PDS methods). For 8 of the 9 procedures, recommended PDS identified relatively more deep SSIs after discharge than did passive PDS. The percentage of postdischarge deep SSIs identified ranged from $1 \%$ for colon resection with passive PDS to $79 \%$ for knee prosthesis with recommended PDS.

TABLE 4. Comparison of the Number of Deep Surgical Site Infections (SSIs) Identified by Recommended Postdischarge Surveillance (PDS) and by Passive PDS During and After Hospitalization, According to Surgical Procedure

\begin{tabular}{|c|c|c|c|c|}
\hline & \multicolumn{2}{|c|}{ Recommended PDS } & \multicolumn{2}{|c|}{ Passive PDS } \\
\hline & $\begin{array}{l}\text { No. of deep } \\
\text { SSIs } \\
\text { that } \\
\text { occurred in } \\
\text { the hospital }\end{array}$ & $\begin{array}{c}\text { No. (\%) of deep } \\
\text { SSIs } \\
\text { that occurred } \\
\text { after } \\
\text { discharge }\end{array}$ & $\begin{array}{l}\text { No. of deep } \\
\text { SSIs } \\
\text { that } \\
\text { occurred in } \\
\text { the hospital }\end{array}$ & $\begin{array}{c}\text { No. (\%) of deep } \\
\text { SSIs } \\
\text { that occurred } \\
\text { after } \\
\text { discharge }\end{array}$ \\
\hline Knee prosthesis surgery & 11 & $41(79)$ & 8 & $26(76)$ \\
\hline Appendectomy & 7 & $23(77)$ & 34 & $14(29)$ \\
\hline $\begin{array}{l}\text { Revision of total hip } \\
\text { prosthesis }\end{array}$ & 9 & $5(63)$ & 18 & $8(31)$ \\
\hline Total hip prosthesis surgery & 34 & $56(62)$ & 48 & $57(54)$ \\
\hline $\begin{array}{l}\text { Femoropopliteal or } \\
\text { femorotibial bypass }\end{array}$ & 12 & $12(50)$ & 18 & $11(38)$ \\
\hline $\begin{array}{l}\text { Replacement of head of } \\
\text { femur }\end{array}$ & 33 & $14(30)$ & 32 & $15(32)$ \\
\hline Reconstruction of aorta & 8 & $3(27)$ & 15 & $4(21)$ \\
\hline $\begin{array}{l}\text { Anterior resection of } \\
\text { rectosigmoid }\end{array}$ & 20 & $5(20)$ & 50 & $6(11)$ \\
\hline Colon resection & 35 & $9(20)$ & 133 & $2(1)$ \\
\hline
\end{tabular}

a Procedures in which at least 10 deep SSIs were identified by both PDS methods.

In addition, we investigated differences in the duration of hospital stay for patients with and patients without SSIs, considering only procedures where one of the recommended PDS methods was used and at least 100 operations and 10 SSIs were registered. The median hospital stay for patients without an SSI varied from 3 days for hernia inguinalis surgery to 17 days for removal of an infected hip prosthesis. For all types of procedures together, patients with an SSI detected during hospitalization had a longer median hospital stay (23 days) than did patients without an SSI (10 days) and patients with a postdischarge SSI ( 9 days). Thus, an SSI that developed before discharge resulted, on average, in 14 extra 
hospital days, ranging from 5 extra bed days for a cesarean section to 42 extra bed days for a femoropopliteal or femorotibial bypass (values not corrected for risk factors).

Figure 2 shows the percentage of all SSIs (both superficial and deep together) according to postoperative day, that developed during the hospital stay and after discharge. The peak for SSIs recorded during the patient's hospital stay was during postoperative week 1 , and the peak for SSIs recorded after discharge was during postoperative week 2 . Of the infections detected during the hospital stay, $90 \%$ of the superficial SSIs were detected at day 16 , and $90 \%$ of the deep SSIs were detected at day 20 . Of the infections detected after discharge, $90 \%$ of the superficial SSIs were detected at day 25 , and $90 \%$ of the deep SSIs was detected at day 122 .

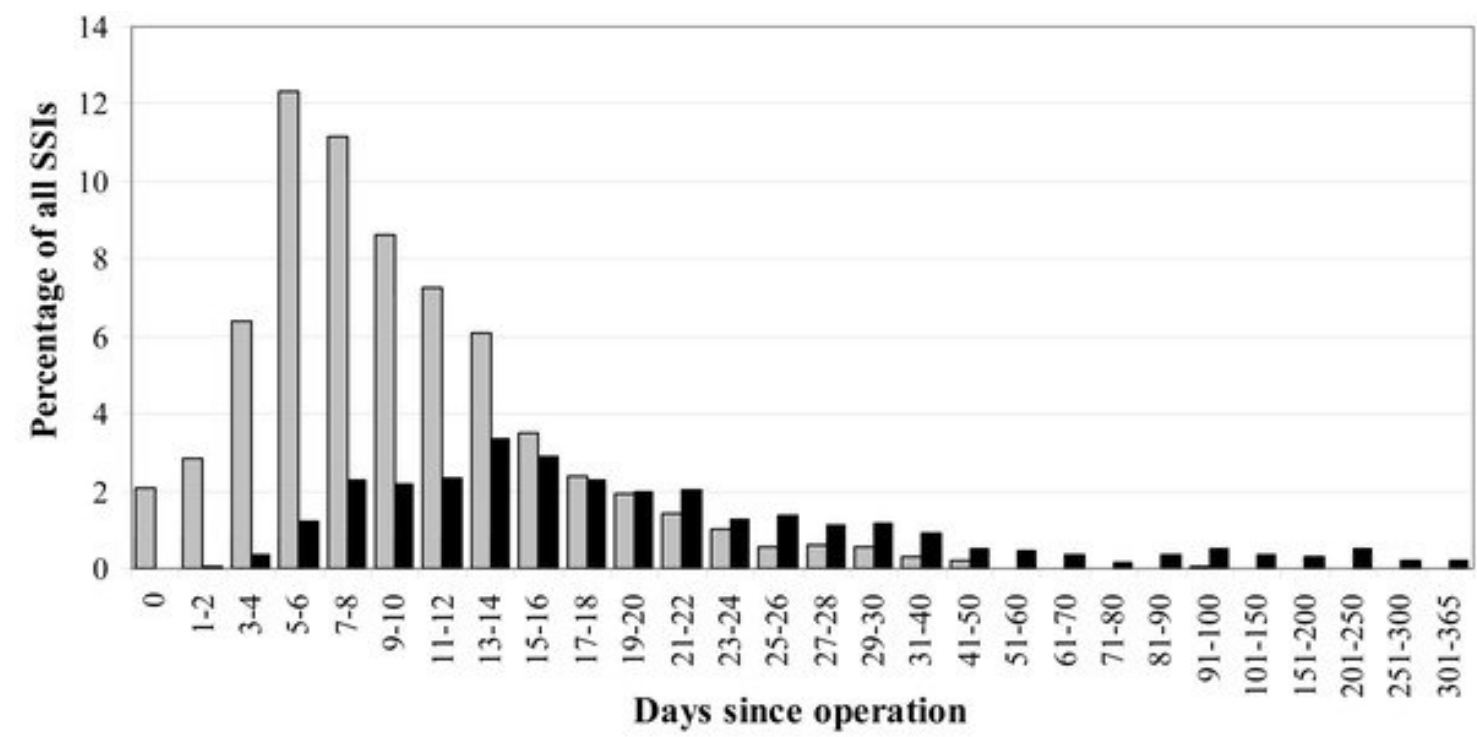

SSIs during stay $\mathbf{m}$ SSIs after discharge

FIGURE 2. Time curve showing the percentage of all SSIs (both superficial and deep, with data from all procedures and all postdischarge surveillance methods together) that developed during hospitalization and after discharge, by postoperative day.

We also examined whether there was a relationship between the time to infection and the wound contamination class. For procedures in contamination class 1 , the median time to infection was 12 days; for contamination class 2 , it was 9 days; for contamination class 3 , it was 9 days; and for contamination class 4 , it was 7 days. For procedures in contamination class 1,37\% of SSIs were found after discharge; for contamination class 2, 22\%; for contamination class 3, 17\%; and for contamination class $4,15 \%$. The distribution of the time to infection was significantly different between wound contamination classes $(P<.001)$. 


\section{DISCUSSION}

The increasing trend towards more outpatient surgery and a shorter postoperative hospital stay makes it more difficult for infection control professionals to detect all SSIs. Therefore, PDS becomes increasingly important to obtain correct and complete-and thus useful-infection frequency data. According to our national surveillance data, up to $79 \%$ of SSIs (for appendectomy) occurred after the patient's discharge from the hospital.

The methods for PDS recommended by the Dutch national surveillance network, PREZIES, are addition of a special registration card to the outpatient medical record, on which the surgeon notes clinical symptoms and whether a patient developed an SSI according to the definitions; an alternative is examination of the outpatient medical record. These methods are considered to be achievable and reliable for most Dutch hospitals, because almost every patient is seen by their surgeon after discharge. Besides the recommended methods, other PDS methods could be used, such as telephone interviews or questionnaires filled in by the surgeon or patient. The disadvantage of questionnaires is that by no means all of them will be returned. Moreover, self-assessments by patients are not very reliable. Telephone interviews by the infection control professional can result in more reliable information but are very time-consuming. Questionnaires filled in retrospectively by surgeons sometimes have a low sensitivity. Direct observation of the wound by a surgeon or infection control professional (one who is familiar with the definition of an SSI) has seemed more reliable, but is also more expensive and time-consuming. 3,12,19-22

Another issue, besides the costs and time consumption, is the follow-up rate. Rates of follow-up can be influenced by socioeconomic conditions, levels of education, population density, availability of transport and population mobility. When follow-up is inadequate, the follow-up "responders" may no longer be representative of the original population. A potential bias is introduced (attrition bias). ${ }^{23}$ The follow-up rates in Dutch hospitals are high, as (almost) every patient returns to the hospital or outpatient clinic after discharge. However, our surveillance data cannot provide sensitivity estimates for our recommended PDS methods because we could not compare it with a "gold standard."

If one of the two methods for PDS recommended by PREZIES was used, a higher proportion of SSIs were found after discharge (43\%) than if another active method $(30 \%)$ or passive surveillance $(25 \%)$ was used. No distinction between the two recommended PDS methods could be made, as it was not separately recorded which of the two methods was used. It is favorable that, since 1999, the relative number of Dutch hospitals participating in PREZIES that used a recommended PDS method has increased, up to $50 \%$ in 2003. This increase since 1999 might be explained by the fact that the importance of using the recommended methods has been brought to the attention of healthcare professionals multiple times since 2000; for example, during the yearly workshops organized by the PREZIES network and during validation visits.

It is remarkable that for some surgical specialties (peripheral blood vessel surgery and mammary surgery), PDS is rarely performed according to one of the recommended methods (for $14 \%$ and $14 \%$ of operations, respectively), whereas many SSIs occur after discharge ( $51 \%$ and $63 \%$ of SSIs, respectively). We should focus on these specialties and try to convince the surgeons and infection control professionals of the importance of performing PDS for these specialties. 
The reported percentage of SSIs found after discharge differs greatly between countries. This depends on the type of procedures for which surveillance is performed but might also be influenced by differences in PDS methods and differences in length of hospital stay. For example, for knee prosthesis surgery, Friedman et al. ${ }^{24}$ found $72 \%$ of the SSIs after discharge, whereas we found $64 \%$ after discharge. For cesarean section, 2 studies recorded $83 \%$ of the SSIs after discharge, ${ }^{20,25}$ whereas we found $68 \%$ after discharge (data not shown). Hardly any study has examined and reported the number of SSIs discovered through passive surveillance. Medina-Cuadros et al. ${ }^{26}$ found $14 \%$ of SSIs after discharge by passive surveillance. In our study, $25 \%$ of SSIs were detected by passive surveillance after discharge. Differences in the performance of PDS methods makes it hard to compare SSI rates between hospitals or between countries, especially when information on PDS is not registered, which for example is the case for the National Nosocomial Infections Surveillance System data.

In our study, the number of SSIs recorded after discharge depended on the wound contamination class. This is partly because patients with a higher wound contamination class have a longer hospital stay. ${ }^{26,27}$ However, the time to infection was also shorter with increasing wound contamination class. A likely explanation is that contamination during surgery contributes to wound infection, so that infection following procedures classified as "dirty" is likely to develop quickly, but infection following a procedure classified as "clean" is likely to present later, usually after hospital discharge.

We found relatively fewer superficial SSIs after discharge than before discharge from the hospital. This is partly caused by the difference in definition; superficial SSIs may occur until 30 days after surgery, and deep SSIs may occur until 1 year after surgery, for a synthetic (non-human-derived) implant. Another explanation might be that superficial infections are less severe than deep SSIs. Therefore, patients with superficial SSIs will less often return to the hospital, which results in an underestimation of the number of superficial SSIs that occur after hospital discharge. However, even with passive PDS, 38\% of the postdischarge SSIs were superficial. Apparently, SSIs are noticed and registered even though no active PDS method is used.

The way passive PDS is performed will differ between hospitals. Some might not register postdischarge SSIs at all, whereas others might watch carefully for readmitted patients with an SSI. However, this detailed information on the performance of passive PDS by hospital is not available.

With use of a recommended method for PDS, the percentage of all deep SSIs that developed after discharge was highest for knee prosthesis surgery, appendectomy, revision of total hip prosthesis, and total hip prosthesis surgery. In particular, PDS should be performed for surveillance of such procedures, because deep SSIs are more severe than superficial SSIs and have more negative consequences for patients and higher costs.

Because of the more severe side effects, a patient with a deep SSI is more likely to return to the hospital after discharge, at which time a deep SSI can be found by passive surveillance. However, this assumption is not confirmed by the PREZIES data, because the ratio of deep SSIs identified after discharge to deep SSIs identified in the hospital was lower for nearly all surgical procedures with use of passive PDS, compared with use of a recommended method for PDS. Thus, it seems that not all patients with a deep SSI return to the hospital where the surgery was performed. In addition, passive PDS might have a lower sensitivity. 
Some studies have shown that there are important epidemiological differences between in-hospital SSIs and postdischarge SSIs. ${ }^{15,26,28,29}$ Although inpatients with SSIs were characterized by known risk factors, patients with a postdischarge SSI were not. For most of the classic risk factors, patients with postdischarge SSI were more similar to noninfected patients than to patients with an in-hospital SSI. If postdischarge SSIs are taken into account in the analysis of risk factors for SSI, it would decrease the degree of association between classic risk factors and SSI risk to an extent related to the proportion of postdischarge SSIs among all SSIs. ${ }^{26}$

Data in the present study also demonstrated differences in risk factors between patients with in-hospital SSIs and patients with postdischarge SSIs according to the type of surgical procedure. However, there were no obvious risk factors for in-hospital or postdischarge SSI that were similar for several surgical procedures (data not shown).

In summary, it appears that for comparison of SSI rates, it is extremely important to know whether and how PDS was performed. In each report, publication, or communication, the PDS method used and the proportion of patients seen after discharge should be given routinely. In the Dutch SSI surveillance system, recording the PDS method used is compulsory; however, it is not mandatory to record whether each patient is seen again by the surgeon after discharge. But we do regularly emphasize the importance of registering the latter information.

Because surveillance that includes PDS yields the most correct infection rates (ie, those with the smallest underestimations), it is best to perform PDS, especially if conducting surveillance for procedures that usually have a short length of stay and/or many infections that occur after discharge.

In the current study, performance of active PDS appeared to be extremely important for most surgical procedures. Because of the significance of PDS, the yearly Dutch national reference SSI rates for each type of surgical procedure are given separately for (1) operations in which PDS was performed according to one of the two recommended methods (in-hospital and postdischarge SSIs are reported together) and for (2) all operations with or without PDS performed, in which only the in-hospital SSIs were reported. Therefore, each hospital can compare their own infection rates with appropriate national reference numbers. Ideally, all hospitals would perform PDS in the same way. We believe we have found a feasible and sensitive method for PDS that may be suitable for use internationally, in circumstances in which patients routinely return to the hospital for postdischarge checkup and healthcare workers can be convinced of the importance and value of PDS.

\section{ACKNOWLEDGMENTS}

We gratefully acknowledge all the infection control practitioners, medical specialists, and nurses at the participating hospitals for their invaluable contribution to the collection of data. 


\section{REFERENCES}

1. National Nosocomial Infections Surveillance (NNIS) report, data summary from October 1986-April 1996, issued May 1996. A report from the National Nosocomial Infections Surveillance (NNIS) System. Am J Infect Control 1996; 24:380-388.

2. Kirkland KB, Briggs JP, Trivette SL, Wilkinson WE, Sexton DJ. The impact of surgical-site infections in the 1990s: attributable mortality, excess length of hospitalization, and extra costs. Infect Control Hosp Epidemiol 1999; 20:725-730.

3. Sands K, Vineyard G, Platt R. Surgical site infections occurring after hospital discharge. J Infect Dis 1996; 173:963-970.

4. Martone WJ, Nichols RL. Recognition, prevention, surveillance, and management of surgical site infections: introduction to the problem and symposium overview. Clin Infect Dis 2001;33(Suppl 2):S67-S68.

5. Gaynes RP, Culver DH, Horan TC, Edwards JR, Richards C, Tolson JS. Surgical site infection (SSI) rates in the United States, 1992-1998: the National Nosocomial Infections Surveillance System basic SSI risk index. Clin Infect Dis 2001;33(Suppl 2):S69-S77.

6. Holtz TH, Wenzel RP. Postdischarge surveillance for nosocomial wound infection: a brief review and commentary. Am J Infect Control 1992; 20:206-213.

7. Brown RB, Bradley S, Opitz E, Cipriani D, Pieczarka R, Sands M. Surgical wound infections documented after hospital discharge. Am J Infect Control 1987; 15:54-58.

8. Smith RL, Bohl JK, McElearney ST, et al. Wound infection after elective colorectal resection. Ann Surg 2004; 239:599-605.

9. Perencevich EN, Sands KE, Cosgrove SE, Guadagnoli E, Meara E, Platt R. Health and economic impact of surgical site infections diagnosed after hospital discharge. Emerg Infect Dis 2003; 9:196-203.

10. National Nosocomial Infections Surveillance (NNIS) System Report, data summary from January 1992 through June 2003, issued August 2003. Am J Infect Control 2003; 31:481498.

11. Mangram AJ, Horan TC, Pearson ML, Silver LC, Jarvis WR. Guideline for Prevention of Surgical Site Infection, 1999. Centers for Disease Control and Prevention (CDC) Hospital Infection Control Practices Advisory Committee. Am J Infect Control 1999; 27:97-132.

12. Manian FA. Surveillance of surgical site infections in alternative settings: exploring the current options. Am J Infect Control 1997; 25:102-105.

13. de Haas R, Mintjes-de Groot AJ, Geubbels ELPE, van den Berg JMJ, de Boer AS. Inventarisatie van surveillance na ontslag in het PREZIES-project. Bilthoven, The Netherlands: National Institute for Public Health and the Environment and Utrecht, The Netherlands; The Dutch Institute for Healthcare Improvement; 1998.

14. Avato JL, Lai KK. Impact of postdischarge surveillance on surgical-site infection rates for coronary artery bypass procedures. Infect Control Hosp Epidemiol 2002; 23:364-367.

15. Delgado-Rodriguez M, Gomez-Ortega A, Sillero-Arenas M, Llorca J. Epidemiology of surgicalsite infections diagnosed after hospital discharge: a prospective cohort study. Infect Control Hosp Epidemiol 2001; 22:24-30.

16. Horan TC, Gaynes RP. Surveillance of nosocomial infections. In: Mayhall CG, ed. Hospital Epidemiology and Infection Control. 3rd ed. Philadelphia: Lippincott Williams and Wilkins; 2004:1659-702.

17. Infection Prevention Working Party (WIP). Registration of hospital infections. Guideline 25b. Leiden: Leiden University Medical Center; 2001.

18. Owens WD, Felts JA, Spitznagel EL Jr. ASA physical status classifications: a study of consistency of ratings. Anesthesiology 1978; 49:239-243.

19. Manian FA, Meyer L. Adjunctive use of monthly physician questionnaires for surveillance of surgical site infections after hospital discharge and in ambulatory surgical patients: report of a seven-year experience. Am J Infect Control 1997; 25:390-394. 
20. Noy D, Creedy D. Postdischarge surveillance of surgical site infections: a multi-method approach to data collection. Am J Infect Control 2002; 30:417-424.

21. Taylor EW, Duffy K, Lee $\mathrm{K}$ et al. Surgical site infection after groin hernia repair. $\mathrm{Br} \mathrm{J}$ Surg 2004; 91:105-111.

22. Whitby M, McLaws ML, Collopy $B$, et al. Post-discharge surveillance: can patients reliably diagnose surgical wound infections? J Hosp Infect 2002; 52:155-160 .

23. Kent $P$, McDonald $M$, Harris $O$, Mason $T$, Spelman D. Post-discharge surgical wound infection surveillance in a provincial hospital: follow-up rates, validity of data and review of the literature. ANZ J Surg 2001; 71:583-589.

24. Friedman C, Sturm LK, Chenoweth C. Electronic chart review as an aid to postdischarge surgical site surveillance: increased case finding. Am J Infect Control 2001; 29:329-332.

25. Couto RC, Pedrosa TM, Nogueira JM, Gomes DL, Neto MF, Rezende NA. Post-discharge surveillance and infection rates in obstetric patients. Int J Gynaecol Obstet 1998; 61:227231.

26. Medina-Cuadros M, Sillero-Arenas M, Martinez-Gallego G, Delgado-Rodriguez M. Surgical wound infections diagnosed after discharge from hospital: epidemiologic differences with inhospital infections. Am J Infect Control 1996; 24:421-428.

27. Law DJ, Mishriki SF, Jeffery PJ. The importance of surveillance after discharge from hospital in the diagnosis of postoperative wound infection. Ann R Coll Surg Engl 1990; 72:207-209.

28. Eriksen HM, Chugulu S, Kondo S, Lingaas E. Surgical-site infections at Kilimanjaro Christian Medical Center. J Hosp Infect 2003; 55:14-20.

29. Reid R, Simcock JW, Chisholm L, Dobbs B, Frizelle FA. Postdischarge clean wound infections: incidence underestimated and risk factors overemphasized. ANZ J Surg 2002; 72:339-343. 